\title{
Does the colour of the mug influence the taste of the coffee?
}

\author{
George H Van Doorn ${ }^{*}$, Dianne Wuillemin ${ }^{1}$ and Charles Spence ${ }^{2}$
}

\begin{abstract}
Background: We investigated whether consumers' perception of a café latte beverage would be influenced by the colour (transparent, white or blue) of the mug from which it was drunk.

Results: In experiment 1, the white mug enhanced the rated "intensity" of the coffee flavour relative to the transparent mug. However, given slight physical differences in the mugs used, a second experiment was conducted using identical glass mugs with coloured sleeves. Once again, the colour of the mug was shown to influence participants' rating of the coffee. In particular, the coffee was rated as less sweet in the white mug as compared to the transparent and blue mugs.

Conclusions: Both experiments demonstrate that the colour of the mug affects people's ratings of a hot beverage. Given that ratings associated with the transparent glass mug were not significantly different from those associated with the blue mug in either experiment, an explanation in terms of simultaneous contrast can be ruled out. However, it is possible that colour contrast between the mug and the coffee may have affected the perceived intensity/sweetness of the coffee. That is, the white mug may have influenced the perceived brownness of the coffee and this, in turn, may have influenced the perceived intensity (and sweetness) of the coffee. These results support the view that the colour of the mug should be considered by those serving coffee as it can influence the consumer's multisensory coffee drinking experience. These results add to a large and growing body of research highlighting the influence of product-extrinsic colour on the multisensory perception of food and drink.
\end{abstract}

Keywords: Colour contrast, Simultaneous contrast, Coffee, Mug, Colour, Taste

\section{Background}

In Australia alone, around a billion cups of coffee are consumed in cafés, restaurants and other outlets each and every year [1]. Even Britain, a nation famous for its fondness for tea, has, in recent years, seen a dramatic rise in its coffee consumption, with an estimated 70 million cups drunk each day [2]. Given the economic incentive to keep consumers drinking coffee, café owners, restaurateurs, crockery designers and manufacturers ought, presumably, to be interested in anything that can help to enhance the multisensory coffee drinking experience for their clientele cf. [3].

The idea behind experiment 1 came about serendipitously. During a conversation between the first author (GV) and a barista, the latter reported that when coffee

\footnotetext{
* Correspondence: george.vandoorn@federation.edu.au

${ }^{1}$ School of Health Sciences and Psychology, Federation University Australia, Northways Road, Churchill, Victoria 3842, Australia

Full list of author information is available at the end of the article
}

is consumed from a white, ceramic mug, it tastes more bitter than when drunk from a clear, glass mug instead; note that these two mug types are amongst the most commonly used vessels to serve coffee in Australian cafés and restaurants. In the present study, we therefore sought to establish the validity of this claim which, to our knowledge, has not been described previously. Indeed, as recently highlighted by Spence and Wan [4], there is a paucity of research on the psychological impact of the receptacles that we use to drink from.

The notion that the colour of the receptacle/plateware can impact taste/flavour perception might relate to Piqueras-Fiszman et al.'s [5] research putatively showing that colour contrast resulted in a red, strawberryflavoured mousse presented on a white plate being rated as $10 \%$ sweeter and $15 \%$ more flavourful than when exactly the same food was presented on a black plate, see $[6,7]$ for an extension of this work; see [8] for an explicit attempt to evaluate the colour contrast account. While 
contrast represents one plausible explanation for such results, it is important to note that there are also several other possible mechanisms (e.g., priming) that may explain the influence of product-extrinsic colour on taste/ flavour ratings. Taking the principal of colour contrast one stage further, and given the conversation with the barista, it was proposed that brown may be associated with bitterness (or, perhaps, is negatively associated with sweetness [9]). If taste were to be affected crossmodally by colour contrast, then coffee that is tasted from a white mug should be rated as somewhat more bitter than exactly the same coffee when consumed from a transparent mug instead.

It is possible that another contrast mechanism (i.e., simultaneous contrast) might affect the perception of taste $[10,11]$. Here, if light, opaque, milky brown coffee were to be associated with bitterness, then a light blue mug/surrounding should intensify the brown of the coffee because blue is brown's complementary colour $[6,12]$. This, in turn, would be expected to elevate ratings of bitterness relative to the same coffee when served in a transparent mug. Some famous examples of the use of simultaneous contrast are Heinz's ${ }^{\text {тм }}$ use of a greenishblue can to set off the red-orange colour of their beans and sauce and Cadbury's ${ }^{\mathrm{Tn}}$ use of purple packaging to enhance the colour of their chocolate.

Although many studies have been published on colour-flavour interactions over the years, see [13] for a review, very little has been published to date specifically looking at crossmodal influences on the perception of coffee. This absence is surprising given, as we saw above, how many cups of coffee are drunk every day. In terms of the limited research that has been conducted specifically in this area, Favre and November [14] offered 200 people coffee from four different jars, i.e., brown, red, blue and yellow. Seventy-three percent of the participants reported that the coffee served from the brown container was too strong, whereas $80 \%$ of women felt that the coffee served from the red receptacle had a richer, fuller aroma. The blue jar suggested a milder aroma to most and the coffee in the yellow container was rated as coming from a weaker blend.

Meanwhile, Guéguen and Jacob [15] had 120 people drink coffee from four different coloured cups (blue, green, yellow and red). The participants had to indicate which coffee was the warmest (in terms of its temperature). Thirty-eight percent of the participants reported that the coffee served from the red cup was the warmest, followed by yellow (28.3\%), green (20.0\%) and, finally, blue (13.3\%). Note that these differences were statistically significant. In summary, the colour of the cup can be added to the list of factors that have now been demonstrated to influence various aspects of the coffee drinking experience. This list also includes whether or not the coffee had an eco-friendly origin [16] and any branding cues [17].

Based on previous work and anecdotal evidence, we explored the impact of the colour of a receptacle on people's coffee drinking experience. If extrinsic cues influence a consumer's experience of coffee, and if taste is affected by contrast effects, coffee tasted/drunk from a white mug should be rated as more bitter than from a clear mug instead. Given Piqueras-Fiszman et al.'s [5] and Stewart and Goss' [7] work with strawberry mousse and cheesecake, respectively, we thought that it is possible that the brown-bitter association might be enhanced by colour contrast. However, and with regard to the colour of coffee and the colour of the immediate surroundings against which it is presented, simultaneous contrast might be at work. Specifically, the brown of the coffee may be intensified if the coffee is served from a light blue mug. It should be noted that factors other than contrast effects can influence perception. For example, the cup in which the coffee is served may affect us as a function of our perception of the general properties of the cup (i.e., cheap vs. expensive [18], flimsy vs. strong [19]). We have attempted to control these potentially confounding variables in the present study. That said, and to borrow from Piqueras-Fiszman et al. [5], if the colour of the mug affects the way in which people perceive the colour of the coffee, and the colour of the coffee affects the perception of flavour, then the colour of the mug (and any contrast effect that it elicits) would be expected to influence the perceived properties of the coffee (e.g., bitterness).

\section{Results and discussion \\ Experiment 1}

The mug type exerted a significant influence on participants' ratings of the perceived intensity of the café latté, $F(2,15)=4.78, p=.025$ (see Figure 1). Bonferroni-corrected post hoc tests revealed that the café latté was rated as significantly more intense $(p=.026)$ when served from the white, ceramic mug than when served from the clear, glass mug. None of the other comparisons reached statistical significance. The mug type failed to exert any influence on participants' ratings of the other attributes of the café latté (see Table 1).

The white mug enhanced the perceived "intensity" of the coffee flavour relative to the transparent mug. Our hypothesis was that a crossmodal association between brown and bitter exists and that bitterness, and possibly other attributes, would be enhanced by the colour contrast. Although there was no simultaneous contrast effect (i.e., coffee surrounded by its complementary colour was not rated as any more bitter than the coffee presented in either the clear or white mug), it is possible that colour contrast influenced the intensity of the coffee flavour in experiment 1. 


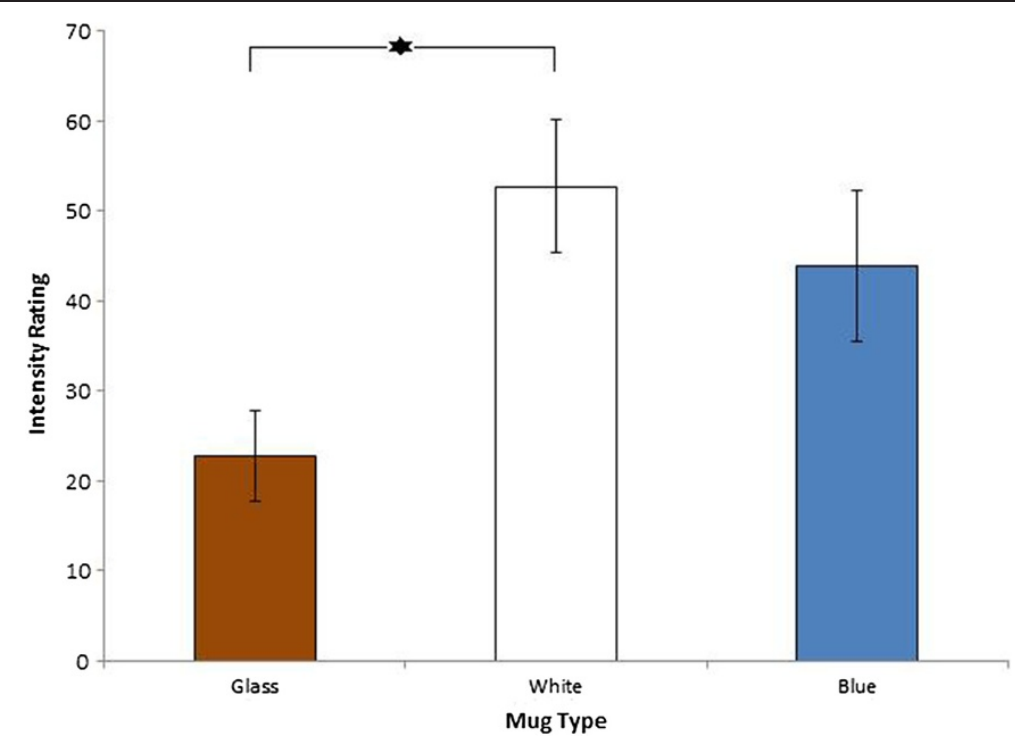

Figure 1 Subjective intensity ratings as a function of the mug type. Errors bars ( $\pm 1 \mathrm{SE})$ are shown.

\section{Experiment 2}

The mug type exerted a significant influence on participants' ratings of the perceived sweetness of the café latté, $F(2,33)=3.57, p=.040$ (see Figure 2). Bonferronicorrected post hoc tests established that the drink was rated as significantly less sweet $(p=.041)$ when served from the white mug relative to the see-through, glass mug or the blue mug. None of the other comparisons reached statistical significance. The mug type failed to exert any influence on participants' ratings of the other attributes of the café latté (see Table 2).

\section{General discussion}

Crossmodal influences refer to the effects that information from one sensory modality can have on the perception of information from another. The main issue explored in this study was whether consumers' perception of a warm café latté would be influenced by the colour (transparent, white or blue) of the mug from which it was served and consumed. Our results clearly demonstrate that the colour of the mug does influence the perceived taste/flavour of coffee.
In the two experiments presented here, it was hypothesised that a crossmodal association between brown and bitter exists and that bitterness, and possibly other attributes, would be enhanced by the colour contrast. In experiment 1 , the white mug was found to enhance the perceived "intensity" of the coffee's flavour relative to the transparent mug. However, given slight differences in the mugs used in experiment 1 , we decided to conduct a follow-up study with identical mugs. Experiment 2 revealed that the white mug diminished the "sweetness" of the coffee flavour relative to the transparent and blue mugs.

Given that ratings associated with the transparent glass mug were not significantly different from those associated with the light blue mug in either experiment, it seems as though simultaneous contrast cannot be used to explain the observed results. However, it is possible that colour contrast influenced the intensity/sweetness of the coffee's flavour. That said, an alternative mechanism (i.e., sensation transference) might also be at play in experiment 1 $[20,21]$. In short, implicit judgments regarding the intensity of the white mug may be transferred to the coffee

Table 1 The mean subjective ratings of the perceived sweetness, aroma, bitterness, quality and acceptability of the coffee

\begin{tabular}{llcccc}
\hline & \multicolumn{5}{c}{ Mean rating } \\
\cline { 2 - 6 } Mug & Sweetness & Aroma & Bitterness & Quality & Acceptability \\
\hline White & $32.35(20.59)$ & $57.33(16.27)$ & $55.67(20.57)$ & $57.35(16.26)$ & $50.35(20.17)$ \\
Blue & $30.52(10.48)$ & $35.57(25.34)$ & $48.38(13.36)$ & $51.67(26.32)$ & $58.70(13.60)$ \\
Glass & $29.82(14.86)$ & $40.38(19.81)$ & $36.23(18.48)$ & $49.40(26.64)$ & $61.48(16.69)$ \\
\hline
\end{tabular}

As a function of mug type (SDs are shown in parentheses). 


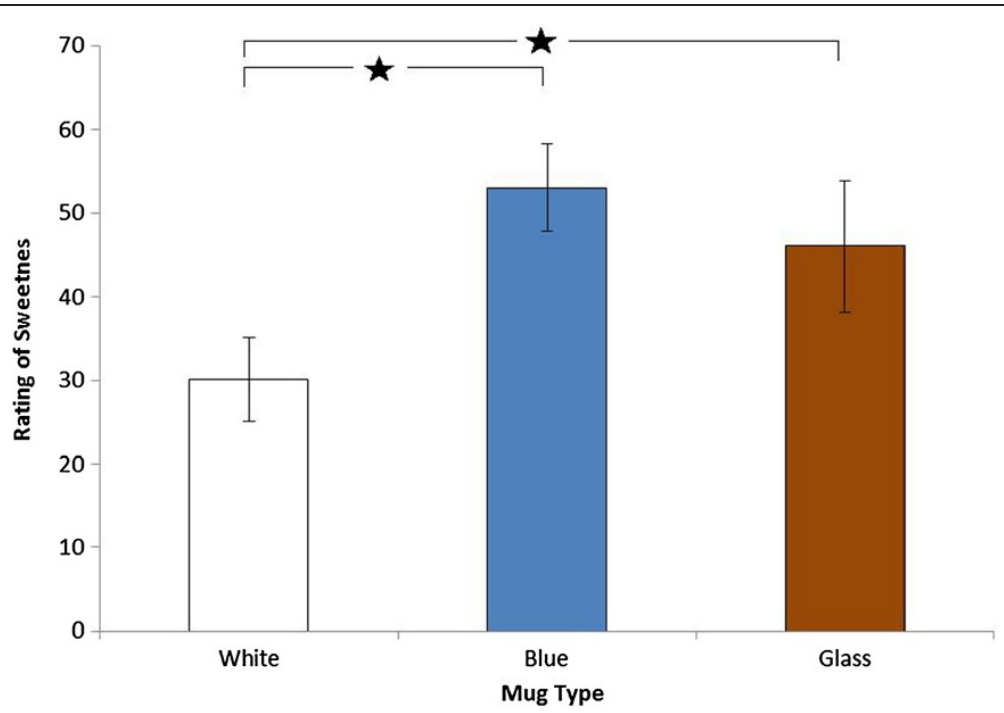

Figure 2 Subjective ratings of sweetness as a function of the mug type. Errors bars ( $\pm 1 \mathrm{SE})$ are shown.

causing it to be perceived as more intense than the coffee served in the other mugs. Given Favre and November's [14] finding that people report coffee served from a brown container to be too strong (i.e., too intense) and our results from experiment 2, it seems unlikely that (1) people would hold an implicit "intensity" judgement for both white and brown colours and (2) 'sensation transference' is the mechanism at work here. Similar to an argument made by Piqueras-Fiszman et al. [5], it seems more plausible to suggest that the white background of the mug may have influenced the perceived brownness of the coffee and that this, in turn, was what influenced the perceived intensity (and sweetness) of the coffee. As we replicate the basic finding that the colour of the mug makes a difference, the correspondence between the visual appearance of the mug and aspects of the flavour suggests that colour contrast mechanisms may be at work here.

Two findings are worth highlighting here: (1) that there is a general trend in experiment 2 towards an increased "intensity" rating (i.e., ratings of intensity were greater for coffee served in the white mug), but this effect failed to reach significance, and (2) the significant intensity and sweetness results of experiments 1 and 2, respectively, might be connected. Note that consumers, as compared to baristas, appear to blur the distinction between 'intensity' and 'bitterness'. Dijksterhuis [22] has suggested that because of the use of the word 'strong' in advertising, consumers often confuse a coffee's strength or intensity with its 'bitterness'-in fact, visual inspection of Tables 1 and 2 reveals that there is a trend in bitterness ratings that mirrors intensity ratings that would support such a view. Furthermore, any reduction in the "sweetness" of the coffee when presented from a white mug might also be expected to signify an increase in perceived bitterness (or strength). As mentioned above, Koch and Koch [9] also found that brown, amongst other colours, was negatively associated with sweetness.

Marketers such as Favre and November [14] have reported an effect of jar colour on perceived coffee aroma. Coffee served in a blue jar was more often judged as having a milder aroma than the same coffee when presented in jars of other colours. By contrast, we observed no effect of blue on aroma or any of the other attributes. Favre and November [14] seem to have documented a

Table 2 The mean subjective ratings of the perceived intensity, aroma, bitterness, quality and acceptability of the coffee as a function of mug type (SDs are shown in parentheses)

\begin{tabular}{lccccc}
\hline & \multicolumn{5}{c}{ Mean rating } \\
\cline { 2 - 6 } Mug & Intensity & Aroma & Bitterness & Quality & Acceptability \\
\hline Bhite & $35.46(28.04)$ & $38.18(24.09)$ & $36.00(31.02)$ & $50.57(22.67)$ & $40.38(29.00)$ \\
Glue & $31.16(6.19)$ & $29.71(15.89)$ & $27.34(14.80)$ & $49.48(17.17)$ & $55.58(19.95)$ \\
\hline
\end{tabular}

As a function of mug type (SDs are shown in parentheses). 


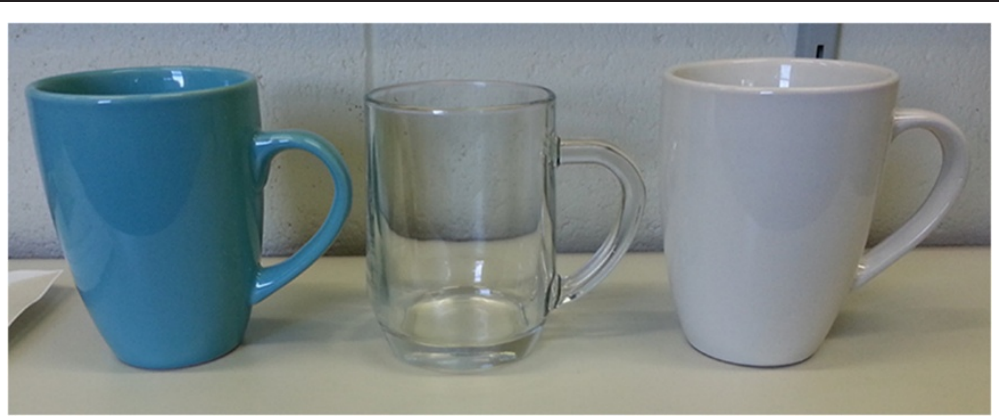

Figure 3 The three mugs used in experiment 1.

simultaneous contrast effect for "mildness" which might be considered to lie at the opposite end of an "intensity" rating scale. Elsewhere, researchers have demonstrated that the colour of plastic vending cups influences people's perception of hot chocolate, such that orange (with a white interior) enhanced the chocolate flavour, as did dark-cream coloured cups which also enhanced sweetness and aroma [23]. Although our findings differ in their details from those of Piqueras-Fiszman and Spence [23], they nevertheless concur at a more general level in demonstrating the importance of the colour of the container/plateware on the consumer's experience of a variety of food and drink products, see also [24]. Our results also help to address the relative paucity of literature on the influence of drinking receptacles as recently highlighted by Spence and Wan [4].

\section{Conclusions}

The results of the two experiments reported in the present study demonstrate that the colour of a container influences people's ratings of the taste/flavour of a warm beverage. The crossmodal effect of the colour of the mug on the flavour of the coffee reported here suggests that café owners, baristas, as well as crockery manufacturers should carefully consider the colour of the mug and the potential effects that its colour may exert over the multisensory coffee drinking experience.

\section{Methods}

\section{Experiment 1}

Eighteen volunteers (nine women) aged between 18 and 62 years $(M=31.5$ years, $\mathrm{SD}=12.2$ years $)$ drank $\sim 200 \mathrm{~mL}$ of café latte $(\sim 135 \mathrm{~mL}$ of full-cream milk and $\sim 65 \mathrm{~mL}$ of coffee). Six people were given their coffee in a white, porcelain mug, six in a transparent, glass mug and six in a blue, porcelain mug (see Figure 3). A between-participants experimental design was used in order to avoid any possible demand characteristics $[6,25]$.

Ethical approval was granted by, and the experiment was carried out in accordance with the regulations of, the Monash University Human Research Ethics Committee (Ref: 2013000270). This project was carried out in compliance with the Helsinki Declaration. The participants gave their written informed consent before the start of the experiment.

The texture of each mug was equivalent (i.e., a smooth, polished exterior). The mugs were as close to identical in terms of their shape, size and weight (white $=375 \mathrm{~g}$, transparent $=367 \mathrm{~g}$, blue $=365 \mathrm{~g}$ ) as possible. We wanted to keep the weight of the mugs similar given findings that

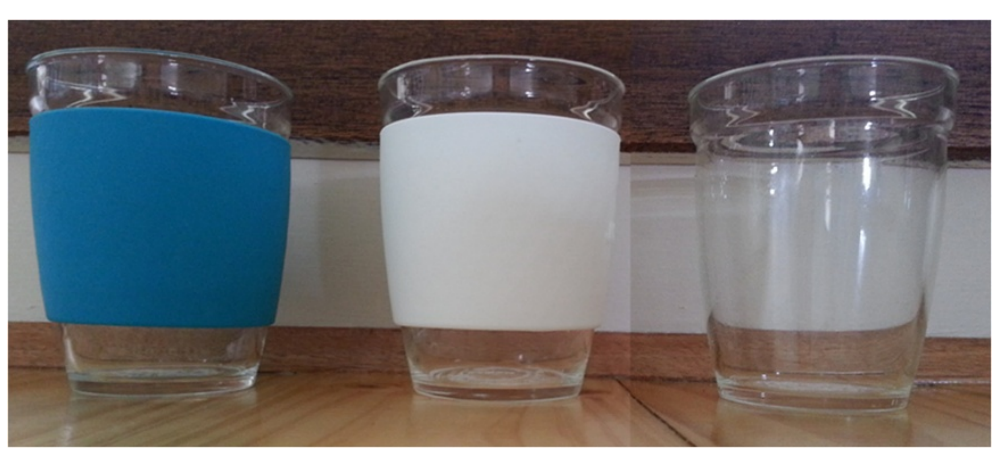

Figure 4 The three mugs used in experiment 2. 
the weight of a container can influence the perceived flavour [18]. Each cup of coffee was made using a DeLonghi Magnifica coffee machine set to "regular" taste just prior to the experiment to ensure the temperature of each was as similar as possible. The same metal spoon was used to stir every cup of coffee (and was cleaned using water between participants). The temperature in the experimental room was kept constant. Gal et al. [26] assessed the effects of room lighting on coffee consumption and reported that individuals who preferred strong coffee drank significantly more under bright lighting than under dim lighting; the opposite was true for those individuals who preferred weaker coffee, see $[27,28]$ for other factors influencing consumption behaviour. As such, we deemed it important to keep the lighting constant. The experimenter was not blind to the hypothesis, but was careful not to give away any hints as to the nature of the experiment. Participants were told that the purpose of the study was to assess certain characteristics of coffee. As an aside, as participants were randomly allocated to each group, it should not matter how they usually take their coffee (e.g., with milk or sugar).

Once the participants had consumed their coffee, they were handed several forms with one 10-cm-long visual analogue scale on each sheet. They rated the bitterness of the coffee by making a mark through the line which provided a quantitative measure of the relevant characteristic. Lines were labelled at their anchors with "0 (Not bitter at all)" and "100 (Very bitter)". The participants also rated the perceived sweetness [0 (not sweet at all), 100 (very sweet)]; aroma [0 (no aroma at all), 100 (very strong aroma)]; flavour intensity [0 (not intense at all), 100 (very intense)]; quality [0 (very low quality), 100 (very high quality)] and acceptability [0 (greatest imaginable dislike), 100 (greatest imaginable like)] of the coffee on similar scales. The scales were presented on separate pages to vary the order of presentation between participants.

\section{Experiment 2}

The results of experiment 1 demonstrated that the café latté was rated as more intense when served in the white, ceramic mug, as compared to the glass mug. However, the mugs differed not only in terms of their colour but there were also very slight differences in terms of their texture and shape (see Figure 3). Furthermore, our sample size was relatively small. Experiment 2 was conducted in order to address these concerns. It is perhaps also worth noting here, in passing, just how many of the previous studies of the colour of the crockery have only involved a single experiment.

Thirty-six volunteers (six men) aged between 17 and 66 years $(M=40.4$ years, $\mathrm{SD}=14.6$ years $)$ were given $\sim 200 \mathrm{~mL}$ of café latte $(\sim 135 \mathrm{~mL}$ of full-cream milk and $\sim 65 \mathrm{~mL}$ of coffee). Twelve people drank from a glass mug with a white rubber grip, 12 from a glass mug with a blue rubber grip and 12 from a transparent, glass mug (see Figure 4).

Ethical approval was granted by, and the experiment was carried out in accordance with the regulations of, the Monash University Human Research Ethics Committee (Ref: 2013000270). This project was carried out in compliance with the Helsinki Declaration. The participants gave their written informed consent before the start of the experiment.

The mugs used in experiment 2 were identical, and the participants were instructed to grasp the mug by the top lip when drinking the coffee (to negate any possible issues associated with the influence of temperature on taste perception). Each cup of coffee was made using a DeLonghi Magnifica coffee machine set to "strong" taste. The participants again rated the attributes of their coffee via 10 -cm-long visual analogue scales, which were presented on separate pages to vary the order of presentation between participants.

\section{Abbreviations}

Vs: versus; $\mathrm{mL}$ : millilitres; g: grams; cm: centimetres; SE: standard error; TM: trade mark.

\section{Competing interests}

The mugs for experiment 2 were provided by Joco ${ }^{\mathrm{TM}}$ cups. They did not contribute to the design or data collection.

\section{Authors' contributions}

GV conceived the study, participated in its design, carried out data collection, performed the statistical analysis and helped draft the final manuscript. DW and CS participated in the design of the study, helped interpret the results and helped write the final manuscript. All of the authors read and approved the final manuscript.

\section{Acknowledgements}

The authors thank Robyn McLean for providing inspiration for this experiment. This research was supported by the AHRC Rethinking the Senses grant (CS). The mugs for experiment 2 were provided by Joco ${ }^{\mathrm{TM}}$ cups.

\section{Author details}

${ }^{1}$ School of Health Sciences and Psychology, Federation University Australia, Northways Road, Churchill, Victoria 3842, Australia. ${ }^{2}$ Department of Experimental Psychology, University of Oxford, South Parks Road, Oxford OX1 3UD, UK.

Received: 19 September 2014 Accepted: 10 October 2014 Published: 25 November 2014

\section{References}

1. Green Food Safety Coach: So how much coffee do we drink? [http://www howsafeisyourfood.com.au/articles/so-how-much-coffee-do-we-drink]

2. Howie M: We're tea sick! Survey shows Britain turning to coffee. [http://www. standard.co.uk/news/uk/were-tea-sick-survey-shows-britain-turning-tocoffee-7895707.html?origin=internalSearch]

3. Spence C, Piqueras-Fiszman B: The Perfect Meal: The Multisensory Science of Food and Dining. Oxford: Wiley-Blackwell; 2014.

4. Spence C, Wan I: Beverage perception and consumption: the influence of the container on the perception of the contents. Food Qual Prefer 2015, 39:131-140.

5. Piqueras-Fiszman B, Alcaide J, Roura E, Spence $C$ : Is it the plate or is it the food? Assessing the influence of the color (black or white) and shape of the plate on the perception of the food placed on it. Food Qual Prefer 2012, 24:205-208. 
6. Piqueras-Fiszman B, Giboreau A, Spence C: Assessing the influence of the colour/finish of the plate on the perception of the food in a test in a restaurant setting. Flavour 2013, 2:24

7. Stewart PC, Goss E: Plate shape and colour interact to influence taste and quality judgments. Flavour 2013, 2:27

8. Bruno N, Martani M, Corsini C, Oleari C: The effect of the color red on consuming food does not depend on achromatic (Michelson) contrast and extends to rubbing cream on the skin. Appetite 2013, 71:307-313.

9. Koch C, Koch EC: Preconceptions of taste based on color. J Psychol 2003, 137:233-242.

10. Lyman B: A psychology of food, more than a matter of taste. New York: Avi, van Nostrand Reinhold; 1989.

11. Brainard DH, Radonjíc A, Wener JS, Chalupa LM: Color constancy. In The new visual neurosciences. Cambridge, MA: MIT Press; 2013:545-556.

12. Ekroll V, Faul F, Niederée R: The peculiar nature of simultaneous colour contrast in uniform surrounds. Vision Res 2004, 2004(44):1765-1786.

13. Spence C, Levitan C, Shankar MU, Zampini M: Does food color influence taste and flavor perception in humans? Chemosens Perc 2010, 3:68-84.

14. Favre JP, November A: Color and communication. ABC-Verlag: Zurich; 1979

15. Guéguen N, Jacob C: Coffee cup color and evaluation of a beverage's "warmth quality". Color Res App 2012, 39:79-81.

16. Sörqvist $P$, Hedblom D, Holmgren M, Haga A, Langeborg L, Nöstl A Kågström J: Who needs cream and sugar when there is eco-labeling? Taste and willingness to pay for "eco-friendly" coffee. PLoS One 2013, 8(12):e80719.

17. Martin D: The impact of branding and marketing on perception of sensory qualities. Food Sci Technol Today Proc 1990, 4(1):44-49.

18. Piqueras-Fiszman B, Harrar V, Alcaide J, Spence C: Does the weight of the dish influence our perception of food? Food Qual Prefer 2011, 22:753-756

19. Krishna A, Morrin M: Does touch affect taste? The perceptual transfer of product container haptic cues. J Consumer Res 2008, 34:807-818.

20. Cheskin L: How to predict what people will buy. New York: Liveright; 1957.

21. O'Mahony M: Gustatory responses to nongustatory stimuli. Perception 1983, 12:627-633.

22. Dijksterhuis G: European dimensions of coffee: rapid inspection of a data set using Q-PCA. Food Qual Prefer 1998, 9:95-98.

23. Piqueras-Fiszman B, Spence C: Does the color of the cup influence the consumer's perception of a hot beverage? I Sens Stud 2012, 27:324-331.

24. Risso P, Maggiono E, Olivero N, Gallace A: The effect of coloured glass on people's perception, expectation and choice of mineral water. Amsterdam: Poster presented at the 15th Annual Meeting of the International Multisensory Research Forum; 2014.

25. Gravetter FJ, Forzano L-A: Research methods for the behavioural science. Belmont, CA: Wadsworth; 2003

26. Gal D, Wheeler SC, Shiv B: Cross-modal influences on gustatory perception. [http://ssrn.com/abstract=1030197]

27. Piqueras-Fiszman B, Spence C: Colour, pleasantness, and consumption behaviour within a meal. Appetite 2014, 75:165-172.

28. Petit C, Sieffermann JM: Testing consumer preferences for iced-coffee: does the drinking environment have any influence? Food Qual Prefer 2007, 18:161-172.

doi:10.1186/2044-7248-3-10

Cite this article as: Van Doorn et al:: Does the colour of the mug

influence the taste of the coffee? Flavour 2014 3:10.

\section{Submit your next manuscript to BioMed Central and take full advantage of:}

- Convenient online submission

- Thorough peer review

- No space constraints or color figure charges

- Immediate publication on acceptance

- Inclusion in PubMed, CAS, Scopus and Google Scholar

- Research which is freely available for redistribution

Submit your manuscript at www.biomedcentral.com/submit
Ciomed Central 